\title{
Numerical Analysis on Orebodies Failure under Shear Loading
}

\author{
Long Wang, Tian Hui Ma*, Wen Dong Zhang \\ Center for Rock Instability and Seismicity Research \\ Dalian University of Technology \\ Dalian, China \\ tianhuima@dlut.edu.cn
}

\begin{abstract}
Orebodies in shear often fail catastrophically. In this paper, the failure process of pillar in shear was studied numerically by the self-developed 2D Rock Failure Process Analysis code (abbreviated as RFPA ${ }^{2 \mathrm{D}}$ ). This work is focused on the appropriate pillar size for safe and economic extraction from orebodies under shear loading. Numerical simulation shows clearly that pillars of different angle and different width to height ratio under different confining pressure have different shear strength and show different failure model. With the increase of pillar angle, the junction of pillar and roof firstly appears stress concentration. It leads to the generation of micro cracks and makes pillar happen failure from surface to inner. Pillars in shear often fail due to reduced confinement and increased brittleness. This paper indicates that RFPA code is a viable tool for providing explanation for failure mechanisms of pillars and guidelines for shear stress consideration in pillar design for orebodies in shear.
\end{abstract}

Keywords- pillar; failure model; pillar size; microcrack; stress concentration

\section{INTRODUCTION}

The problems of pillar size and the pillar stability have been studied for many years. Pillar stability has already been discussed by domestic and foreign scholars. Based on the characteristics of most pillar shear failure, Z. Q. Wang and H. F. Li ${ }^{[1]}$ put forward the concept of pillar shear safety factor, through analysis and comparison, pointed out that it is safe and reliable when the shear safety factor is bigger than 1.2. The actual condition of open mine to underground in Tong Lu Shan south, M. H. Wang and R. B. $\mathrm{Yu}^{[2]}$ determined the thickness of pillar and stope size by using FLAC ${ }^{3 \mathrm{D}}$, and provided reference for the design of related engineering construction. X. J. Wang and X. Feng et al. ${ }^{[3]}$ put forward the reasonable Width formula of Artificial Pillar in Deep Mining, and thought that mining span and mining depth are determined as the main factors affecting the reasonable width of artificial pillar. In practical engineering, the rationality of the related theory is verified by field test. Combined with fracture mechanics and mutation theory, H. Q. Liu, et al. ${ }^{[4]}$ proposed and established the pillar failure formula and the cusp catastrophic model and so on.

Now, most determined size of pillar is based on the limit span method, the empirical formula calculation method and the limit equilibrium analysis ${ }^{[5-6]}$, due to different regions have the geological conditions of differrent disparity, and the mining area is complex, it is not possible to obtain more accurate information. Option of pillar size is related to the stability of stope and the size of the surface subsidence. In the practical engineering, oversize pillar causes the waste of resources ${ }^{[7]}$. In view of the relevant report of the less pillar strength size effect, this paper, by using RFPA $^{2 \mathrm{D}}$--rock failure process analysis based on the theory of the finite element method $^{[8]}$, simulated the strength of different size of pillar, analyzed the failure mechanism, and provided a frame of reference for underground mining engineering construction design.

\section{MODELING}

\section{A. Introduction of model}

In order to analyze the effect of different angle, different width to height ratio under different confining pressure condition on the strength of goaf pillar, pillar width to height ratio is set up to $0.5,1.0,1.5,2.0,2.5$, confining pressure is set up to $0 \mathrm{MPa}, 5 \mathrm{MPa}, 10 \mathrm{MPa}$, $15 \mathrm{MPa}$, and in accordance with the angle of goaf and horizontal, angle is set up to $0^{\circ}, 10^{\circ}, 20^{\circ}, 30^{\circ}, 40^{\circ}$ (as shown in Fig .1). To analyze the influence of different factors and action modes, all models are kept extraction ratio constant at $75 \%$.

Long $\times$ Width of model is $600 \mathrm{~mm} \times 400 \mathrm{~mm}$, goaf height( $\mathrm{Y}$ direction) is $20 \mathrm{~mm}$, divided into $600 \times 400=$ 240000 units. According to the plane strain problem, the model experiment is solved. The whole loading process can be divided into two steps, the first step is to apply loads both in $\mathrm{x}$ and $\mathrm{y}$ direction. After reaching a certain confining pressure, the second step is to remain the unchanged pressure in $\mathrm{x}$ direction and to increase the pressure in y direction until the model is damaged. The load rate is $0.2 \mathrm{MPa} / \mathrm{step}$.

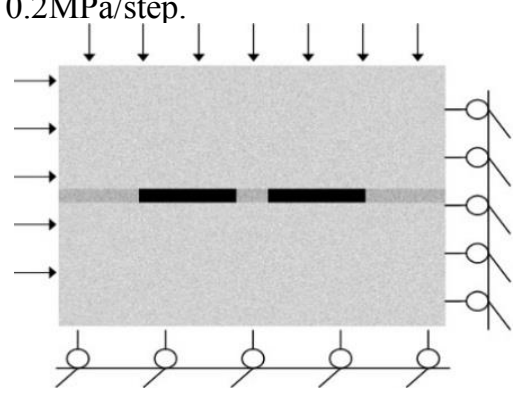

Figure 1. Model and boundary conditions 


\section{B. Mechanical parameters}

Based on Wei-bull distribution, the initial values of material strength and elastic modulus are determined to simulate the heterogeneous nature of rock mass. The parameter $\mathrm{m}$ represents the degree of rock properties. The greater $m$ value is, the more uniform rock properties is. Small value shows the inhomogeneous rock properties. The determination of $\mathrm{m}$ value is determined by

$$
\mathrm{m}=\log _{\left(\sigma / \sigma_{0}\right)}\left(-\ln \sigma / \sigma_{0}\right)
$$

Where $\sigma$ is the nominal stress of rock under uniaxial compression condition, and $\sigma_{0}$ is the effective stress of rock under uniaxial compression. According to this empirical formula, the material macro parameters are converted into microcosmic parameters. On the basis of the actual mechanical property parameters of rock ore bodies in a certain mining area, the rock and ore material parameters of this model are as follows.

TABLE I. MECHANICAL PROPERTIES OF THE MODELS

\begin{tabular}{|c|c|c|c|c|c|}
\hline \multirow{2}{*}{ Type } & \multicolumn{5}{|c|}{ Mechanical properties of the models } \\
\cline { 2 - 6 } & $\mathrm{m}$ & $\sigma / \mathrm{MPa}$ & $\mathrm{E} / \mathrm{MPa}$ & $\mathrm{v}$ & $\varphi /\left(^{\circ}\right)$ \\
\hline Rock mass & 7 & 130 & 70000 & 0.25 & 40 \\
\hline Ore Body & 3 & 60 & 20000 & 0.22 & 35 \\
\hline
\end{tabular}

\section{ANALYSIS OF EXPERIMENTAL RESULTS}

\section{A. Analysis of pillar failure under different pillar width to height ratio}

Pillars are kept ore body to ensure the safety of stope mining process, so the safety and size of pillar are critical. Different pillar size determines whether the economics of extraction or not. Moreover, it has an influence on the safety and failure model of pillar. Pillar instability means rupture when external load reaches ultimate value, compression-shear damage or splitting damage is occurred in the pillar under uniaxial stress until the pillar lose bearing capacity and all pillars cannot resist the mine pressure of roof ${ }^{[7]}$. Accompanying these processes, an elastic stress wave is generated, which travels from the point of origin within the rocks to a boundary, where it is observed as an AE signal ${ }^{[9]}$. In rock, acoustic emission is generated by crack formation under high stress ${ }^{[10]}$. This phenomenon provides a basis for a method which is able to detect zones of microcracking or macro-cracking or highly stressed zones in rock without any knowledge of the mechanical properties or the state of stress ${ }^{[10]}$. The AE is the most direct method to monitor and predict the process of rock burst $^{[11]}$. Generally speaking, rock burst can be classified into three types: fault slip burst, pillar burst, and strain burst $^{[12]}$. This paper mainly studies pillar burst. Due to space limitations, this paper only lists the results of different pillar widths when confining pressure is $5 \mathrm{MPa}$.
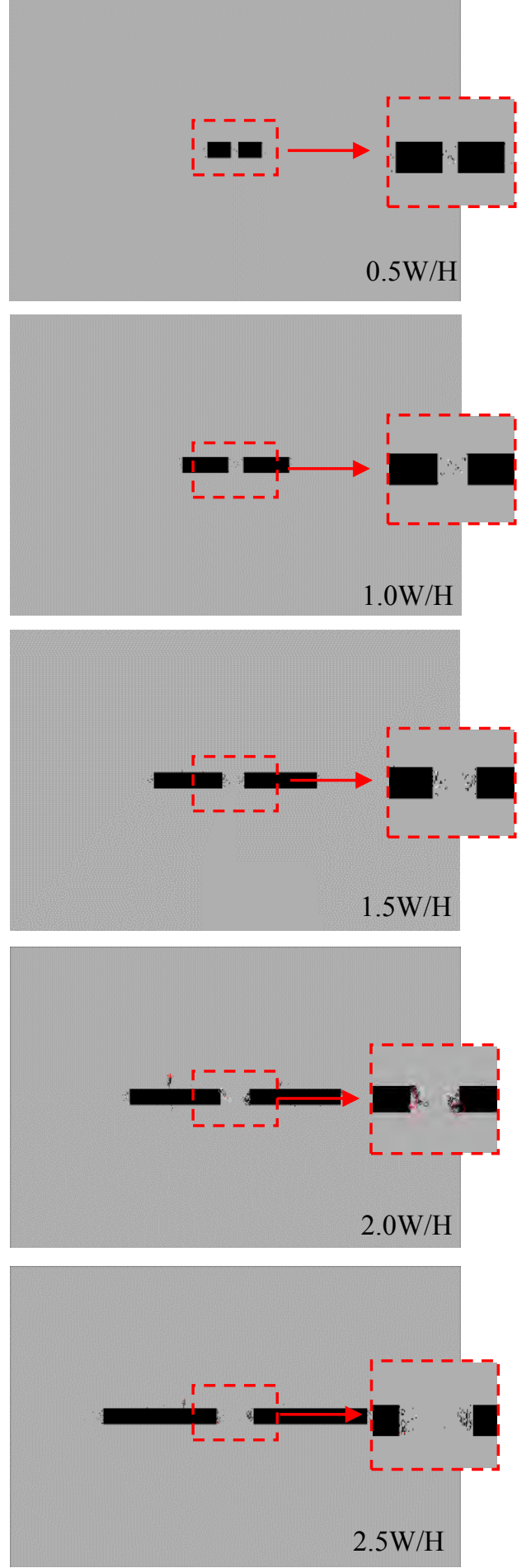

Figure 2 Disruption AE picture of initial stage

The black area in Fig .2 reflects the accumulation of former acoustic emission. While the white represents the acoustic emission of compression-shear damage and the red indicates the acoustic emission of tensile damage. According to Fig .2, when pillar width to height ratio is 0.5 , the acoustic emission appears firstly in the center of pillar. With the increase of loading, the microcracks expand from center to both sides. When the size is 1.0, the appearing location of acoustic emission is started to move, but micro fracture still appears near the center. When the size is 1.5 , pillar damage caused by 
load firstly appears in the surface of pillar. Microcracks are formed at the junction of pillar and roof, and then extend to pillar surface. The size is 2.0 or 2.5 , the position of micro-cracks is similar to its width to height ratio is 1.5. According to this pictures, when pillar width to height ratio is less than 1.5 , pillar micro-cracks are formed from the center to both sides; when the ratio is equal or more than to 1.5 , micro-cracks are extended from the surface of pillar to the pillar center. Shearing stresses value of different width to height ratios under confining pressure of $5 \mathrm{MPa}$ are listed in Table 2:

TABLE II . SHEARING STRESS VALUE

\begin{tabular}{|c|c|c|c|c|c|}
\hline Shearing stress & \multicolumn{5}{|c|}{ Pillar width to height } \\
\cline { 2 - 6 } value (MPa) & 0.5 & 1.0 & 1.5 & 2.0 & 2.5 \\
\hline Shear Strength & $\begin{array}{c}0.5 \\
6\end{array}$ & 14.0 & 19.67 & 30.19 & 33.94 \\
\hline
\end{tabular}

According to Table II, the shear strength is 19.67 $\mathrm{MPa}$ with the ratio of 1.5 , and the shear strength increases by $10.52 \mathrm{MPa}$ to $30.19 \mathrm{Mpa}$ with the width to height ratio of 2.0. But when the ratio is 2.5 , the shear strength is $33.94 \mathrm{MPa}$ which only adds $3.75 \mathrm{MPa}$ to the shear strength with ratio 2.0. Combined with mining economy and security, the optimal width to height ratio of pillar is 2.0 .

\section{B. The effect of different confining pressure on the failure mode of pillar}

A triaxial compression test shows that the brittleness and plasticity of rock are not the intrinsic qualities of it. It is related to the stress state of rock. With the changes of stress, the brittleness and plasticity can be converted $^{[13]}$ as shown in the following figure:

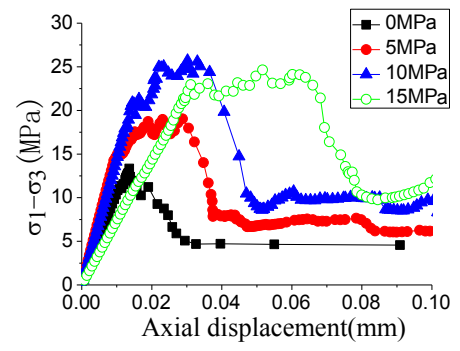

Figure 3. The stress difference curves of different Angle

Fig .3 shows that the strain of pillar before damage increases with the increase of confining pressure. In addition, with the increase of confining pressure, the plasticity of pillar also continually increases. Based on this figures, at the beginning of the load, under the condition of different confining pressures, the stress difference-strain curve of pillar approximatively shows linear behavior. When confining pressure is $0 \mathrm{MPa}$, pillar curve increases to a peak and then fast falls. After reaching a sharp point, the curve gradually flatten out. The failure mode of pillar shows brittle failure. With the increase of confining pressure, curve peak gradually turns into a gentle jagged curve, which indicates that the plasticity of pillar is in enhancement. The curve shape in the top zone is hackly because of the heterogeneity of rock. Damage firstly appears in low-intensity zone or tensile zone. Appeared sharp point is induced by the local rock mass of high strength. According to Fig .3 and formula (2):

$$
\tau_{\max }=\left(\sigma_{1}-\sigma_{3}\right) / 2
$$

The article infers that the maximum shearing stress of pillar is also increased with the increase of confining pressure. The failure mode of pillar gradually turns into plastic failure. However, the smaller confining pressure is loaded, the more obvious the characteristics of brittle failure is.

\section{On the Question of Average Pillar Stress}

Generally, pillar is designed as rectangular. There was a stress concentration phenomenon at the junction of pillar and roof. To determine the pillar average stress, scholars usually used the traditional area allocation $\operatorname{method~}^{[14]}(3)$ :

$$
\sigma_{\mathrm{p}}=\gamma \mathrm{h}\left(1+\mathrm{w}_{\mathrm{o}} / \mathrm{w}_{\mathrm{p}}\right)
$$

Where $\gamma$ is rock density; $h$ is the buried depth; $w_{0}, w_{p}$ respectively are the width of the room and pillar.

Usually, when we use this formula, we tend to ignore the phenomenon. The heterogeneity of rock mass results in inhomogeneous distribution of pillar stress, so the simple method of solving pillar average stress should be improved. In this article, through the RFPA ${ }^{2 \mathrm{D}}$, the stress damage under different angle of pillar is simulated. The maximum principal stress of the two diagonal and horizontal of pillar is extracted to illustrate the problem, as shown in the following figure:
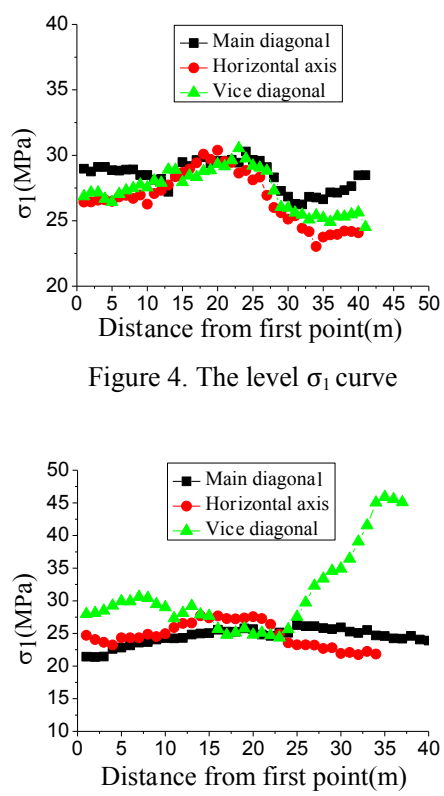

Figure 5. The inclined $\sigma_{1}$ curve

TABLE III. STRESS VALUE OF FOUR ANGLE

\begin{tabular}{|c|c|c|c|c|c|}
\hline \multirow{2}{*}{ Stress value (MPa) } & \multicolumn{5}{|c|}{ Angle } \\
\cline { 2 - 6 } & $0^{\circ}$ & $10^{\circ}$ & $20^{\circ}$ & 30 & $40^{\circ}$ \\
\hline Top left corner & 41.56 & 42.19 & 20.03 & 25.24 & 13.95 \\
\hline Lower left corner & 19.62 & 48.47 & 48.32 & 39.96 & 24.66 \\
\hline Top right corner & 44.16 & 23.72 & 28.55 & 61.64 & 38.89 \\
\hline Bottom right corner & 20.8 & 38.27 & 45.73 & 37.21 & 25.78 \\
\hline
\end{tabular}

On the basis of Fig .4, Fig .5 and Table III, there is a stress concentration phenomenon in pillar. From Fig .4, the stress value of pillar top left corner and 
bottom right corner is higher than the lower left corner, top right corner and horizontal. From Fig .5, as pillar is leaner, the stress concentration phenomenon gradually appears near the pillar lower left corner and upper right corner. The acoustic emission of pillar damage firstly appears in the four corners. With the increase of loading, the acoustic emission expands from the four angle of pillar to both pillar sides. However, pillars still have enough strength, as the following Fig .6. As the load increased, the acoustic emission densely appeared in the center of the pillar, eventually led the pillar to overall shear failure.

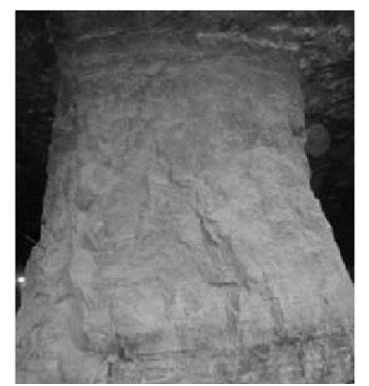

Figure 6. Pillar with corner damage ${ }^{[15]}$

\section{CONCLUSIONS}

Pillars are kept ore body to ensure the safety of stope mining process, so the safety of pillar and pillar size selection are critical. Different pillar size not only determines whether affordable or not, but also has the different safety of pillar, and the failure mode is also different. Through RFPA ${ }^{2 \mathrm{D}}$, the shear failure mode under different confining pressure is simulated and the following conclusions as followed:

(1) When pillar width to height ratio is less than 1.5, pillar micro-cracks are formed from the center to both sides; when the ratio is equal or more than to 1.5 , micro-cracks are extended from the surface of pillar to the pillar center. The shear strength is $19.67 \mathrm{MPa}$ with the ratio of 1.5 , and the shear strength increases by $10.52 \mathrm{MPa}$ to $30.19 \mathrm{Mpa}$ with the width to height ratio of 2.0. But when the ratio is 2.5 , the shear strength is $33.94 \mathrm{MPa}$ which only adds $3.75 \mathrm{MPa}$ to the shear strength with ratio 2.0. Combined with mining economy and security, the optimal width to height ratio of pillar is 2.0 .

(2) The brittleness and plasticity of rock are not the intrinsic qualities of it. As the increase of confining pressure, the maximum shearing stress of pillar also increase, failure of pillar gradually turns into the plastic failure. However, the smaller confining pressure is, the more obvious characteristics of brittle failure is loaded. Pillars in shear often fail due to reduced confinement and increased brittleness;

(3) As pillar is leaner, the stress concentration is formation at the junction of pillar and roof. It lead to the generation of micro cracks. As the load increased, the acoustic emission densely appeared in the center of the pillar, eventually lead the pillar to shear failure all over the pillar. Ignored stress concentration phenomenon of pillar is unreasonable.

\section{ACKNOWLEDGMENT}

The author sincerely acknowledge the assistance of teacher and senior in the preparation of this paper. This research work was supported by the National Key Basic Research Development Plan (973) (No. 2011CB013500,2014CB047100), the Science Fund for Creative Research Groups of the National Natural Science Foundation of China (Grant No. 51121005) and the Chinese National Natural Science Foundation (No. 41202202, 41172265, 51279024).

\section{REFERENCES}

[1] Z. Q.,Wang H. F. Li,"Numerical calculation method for shea safty coefficient of mine pillar," Journal of Mining \& Safety Engineering, vol. 27,June, 2010,pp. 277-280.

[2] M. H. Wang, R. B. Xu, "Numerical simulation of t thickness of pillar under open-pit bot tom and stope dimension". Mining Technology, vol. 9, Sep2009, pp. 14-16.

[3] X. J. Wang, X. Feng, T. B, "Yang, et al. Reasonable width Calculation and Analysis of Artificial Pillar in Deep Mining," Journal of Mining \& Safety Engineering, vol. 29, Jan. 2012, pp. 54-59.

[4] H. Q. Liu, Q. L. Zhang, C. J. Pan, Q. Kang, "Analysis of the failure law and stability of the pillarin open stope mining,"Journal o f M ining \& Safet y Engineering, vol. 28, March 2011,pp. 138-143.

[5] X. D. Zhao, "Stability analysis of insulating pillar of excavation of chambishi copper mine in depth," Chinese Journal of Rock Mechanics and Engineering, vol. 29, May, 2010, pp. 2616-2622.

[6] P. Zou, A. B. Li, Z. Y. Liu, Y. B. Yi, "Determination of thickness of insulating pillar in a limestone mine," Nonferrous Metals, vol. 63, March, 2011, pp. 64-68.

[7] Y. W. Zhong, W. Wan, Y. L. Zhao, J. Liu, M. Wang, "Safety pillar thickness determination and local monitoring in Wengfu phosphate," Mineral Engineering Research, Vol, 27, Sep. 2012, pp. 28-33.

[8] P. Jia, C. A. Tang, G. L. Zhang, "Failure mechanism study on vertically stratified rock mass around deep tunnel," Journal of Northeastern University(Natural Science), vol, 29, Jun. 2008, pp. 893-896.

[9] M. C. He, J. L. Miao, J. L. Feng, "Rock burst process of limestone and its acoustic emission characteristics under truetriaxial unloading conditions," International Journal of Rock Mechanics \& Mining Sciences, vol. 47, Feb. 2010, pp. 286-298, doi:10.1016/j.ijrmms.2009.09.003.

[10] G. Manthei, J. Eisenblätter . "Acoustic emission in study of rock stability," Berlin: Springer-Verlag, 2008, pp. 239-310, doi:10.10 07/978.3.540.69972.9.

[11] G. Q. Chen, T. B. Li , G. F. Zhang, H. Y. Yin, H. Zhang, "Temperature effect of rock burst for hard rock in deep-buried tunnel," Natural Hazards, Vol. 72, Jun. 2014, pp.915-926, doi,10.1007/s11069.014.1042.6.

[12] D. G. F. Hedley, Rockburst handbook for Ontario hardrock min es. Ottawa: Canada Center for Mineral and Energy Technology, 1 992.

[13] M. F. Cai, Rock mechanics and engineering. Beijing: Scince press, 2013

[14] W. J. Liao, "Analysis the effect of water in mined-out area on the ore pillar stability in the gypsum mine," Mining Technology, Vol. 9, May. 2009, pp. 52-53.

[15] C. González-Nicieza, M. I. Álvarez-Fernández, A. MenéndezDíaz, A. E. Álvarez-Vigil, "A comparative analysis of pillar design methods and its application to marble mines," rock mechanics and rock engineering,vol. 39, Nov. 2006,pp. 421-444, doi 10.1007/s00603-005-0078-z. 